\title{
NUMERICAL \& AERODYNAMIC ANALYSIS OF CLARK Y AIRFOIL IN AN OPEN WIND TUNNEL
}

\section{K. HARISH KUMAR, A. SHANTHI SWAROOPINI, SAVITRI VEMIREDDI \& P. HARISHA}

Department of Mechanical Engineering, Vignan's Institute of Information Technology (A), Vizag, India

\begin{abstract}
In the current world almost all the aerodynamic bodies are designed and then analysed for preliminary results. These designs however need to be verified and tested in real time. To study various flow parameters and response of any aerodynamic body under varying conditions and orientations, wind tunnels are used. These tunnels are usually of open or closed types which can be used to conduct studies over flows past any aerodynamic body or structure. The work focuses on aerodynamics design of a Wind Tunnel to simulate and disseminate results of subsonic flows, measurement of lift coefficient (CL) and drag coefficients (CD) which can be used to determine performance of any aerodynamic body. The proposed tunnel was designed based on flow theories to obtain a preliminary design of subsonic tunnel. An open type wind tunnel is designed using CAD tool which is further simulated using ANSYS CFX. The CFD results are examined to decide an optimized design which is then fabricated to carryout experimentation. The model comprises of three parts namely contraction cone which is a convergent tract, test section and a diffuser commonly referred to as diverging tract. The wind speed of the tunnel is varied with the use of a variable transformer. The tunnel manufactured is used to study lift and drag forces acting on different aerodynamic structures and designs. The aerodynamic study of CLARK Y air foilis carried out for testing in wind tunnel after a standard calibration.

KEYWORDS: Open Wind Tunnel, Aerodynamics, Subsonic Flow, CFD Analysis
\end{abstract}

Received: Jun 06, 2020; Accepted: Jun 26, 2020; Published: Aug 25, 2020; Paper Id.: IJMPERDJUN2020880

\section{INTRODUCTION}

A Wind Tunnel is a tool that is used to study the effects of air and the quality of flow and its aerodynamic characteristics. The phenomenon of flow separation to aerofoil is associated with the break-off of the thin layer at the wing surface. How the separation of flow develops to the moment of the full separation, is dependent on various factors: an aerofoil thickness (thin, moderate, and thick), an airflow type (turbulent, laminar, and supercritical), the angle of attack, an aerofoil surface quality (smooth or with roughness), flow conditions (altitude and air turbulence), and Reynolds number [1]. Computational Fluid Dynamics (CFD) has now reached a high degree of confidence so that the researcher in aerodynamics considers that it is an excellent good means to understand the physical reality as well as the measurements acquired during flight tests or in Wind Tunnels. Moreover, taking advantage of the constantly improved reliability of digital means, the concept of computer-aided Wind Tunnels was born. This process aims to correct the results of tests by the results of numerical calculations in conjunction with the tests in the same Wind Tunnel environment. The characteristics of the test are taken into account to determine the effect of the walls, the effect of the support, and, more generally, of anything that could affect the experiment. Furthermore, the numerous Wind Tunnel construction projects in emerging countries show that the use of experiments in the aerodynamics domain is still relevant [2]. Apart from that, the simulation is carried out only to the Test section by considering the Full-scale model of the Wind Tunnel instead of the conventional approach which allows for the 
optimization of flow quality in the entire circuit. The flow quality of the Test section of the guide vanes configurations was more affected Infront of test section rather than behind. Hence, utmost care has to be taken while designing the blades at the turns located in the upstream especially focusing on corners that are aligned with the Test Section[3] but differentiating the effect between the full-scale conditions and unsteady wind loads are necessary to provide an accuracy of wind loads which is a function of reduced frequency [4]. The impact of tripwires at various positions in the contraction section of four Wind Tunnels indicates that the pressure distributions are altered, subsequently, the intensity of the turbulence is reduced and the flow uniformity is improved which effects on the aerofoil placed in the wind tunnel [5]. The CFD analysis with several turbulence models was carried out by examining the pressure and velocity distribution, and fluid turbulence intensity in a test chamber of open type wind tunnel operating at subsonic speeds. A comparison between $\mathrm{k}-\epsilon$ and LES turbulence models has been made where $\mathrm{k}-\epsilon$ model is found to exhibit turbulent intensity of $0.8 \%$ while LES model accounted for $11 \%$ [6]. A thermal-couple anemometer is used to measure the velocity distribution and turbulence intensity of airflow at the nozzle which measures the uniformity of wind speed is above $95 \%$ and that of turbulence intensity was less than two percent [7].The effect of Reynolds number, integral length scale and turbulence intensity effect has studied by testing a Vertical axis wind tunnel (VAWT) prototype by varying turbulent conditions accounting for smooth operation of smaller VAWT inside closely packed environment[8].The investigation is carried out to explore the geometric characteristics and wind flow effects in tunnels of turbulent diffusion flames operated at different positions which shows the flame shape, angle, and drag length[9].To elaborate on the process of wind tunnel test setup, a suitable design choices has to be made without compromising on structural characteristics that effects the wind tunnel performance[10].

\section{DESIGN METHODOLOGY}

An optimized design of wind tunnel is chosen for CFD simulation which is then fabricated to carryout experimentation. Various design considerations have been taken as per the literature studies after which the design is made using a computer aided drafting tool available in CATIA. The designs of all the three parts i.e., contraction cone, test section and diffuser are drafted as represented in figs. 1-3.

\section{Contraction Section}

A contraction section is designed by taking a contraction ratio of 6.16: 1 where contraction section dimensions are taken as specified. The layout is shown in fig. 1

Table 1

\begin{tabular}{|l|c|}
\hline Contraction Section Specifications & \\
\hline Inlet Area & $570 \times 570 \mathrm{~mm}^{2}$ \\
\hline Exit Area & $230 \times 230 \mathrm{~mm}^{2}$ \\
\hline Length of the Contraction Duct & $550 \mathrm{~mm}$ \\
\hline
\end{tabular}




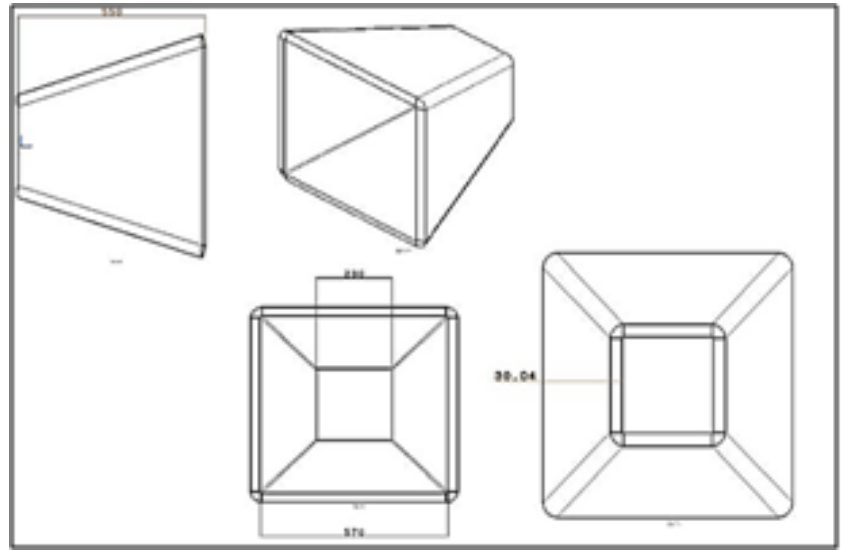

Figure 1: Layout of Contraction Cone.

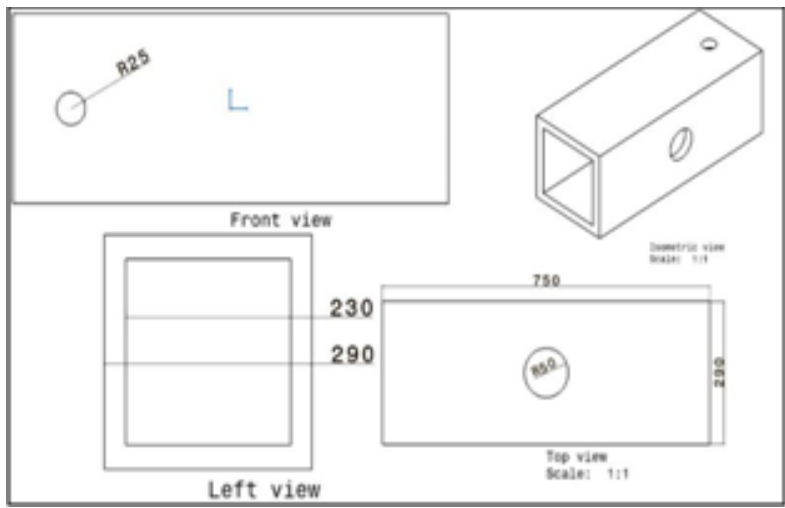

Figure 2: Test Section Layout.

\section{Test Section}

A test section is designed as per the specifications given below thus satisfying basic requirements such as to minimise pressure losses and neglecting frictional effects to a considerable extent. The layout is shown in fig. 2.

Table 2

\begin{tabular}{|l|c|}
\hline \multicolumn{1}{|c|}{ Test Section Specifications } & \\
\hline Square Inlet \& Exit Areas & 230 x $230 \mathrm{~mm}^{2}$ \\
\hline Length of the Contraction Duct & $750 \mathrm{~mm}$ \\
\hline Dynamic Pressure & $245 \mathrm{~N} / \mathrm{m}^{2}$ \\
\hline Velocity of flow & $45 \mathrm{~m} / \mathrm{s}$ \\
\hline
\end{tabular}

\section{Diffuser}

The energy losses at any point in the Wind Tunnel is directly proportional to the cubic velocity at that point. So that, the diffuser works to reduce the velocity with minimum losses and higher back pressure. Generally, it must reduce the velocity without boundary layer separation at the wall. The layout of diffuser section is shown in fig. 3 .

Table 3

\begin{tabular}{|l|c|}
\hline Diffuser Section Specifications & \\
\hline Inlet diffuser width & $230 \mathrm{~mm}$ \\
\hline Outlet Diffuser diameter & $450 \mathrm{~mm}$ \\
\hline Diffuser length & $100 \mathrm{~mm}$ \\
\hline Divergence angle & 3 degrees \\
\hline Aspect ratio & $3.006: 1$ \\
\hline
\end{tabular}




\section{Settling Chamber}

A settling chamber has to be fitted to the entrance of contraction duct which streamlines the flow entering the tunnel thus reducing turbulence and effects caused due to it. It looks as similar to honeycomb structure as shown in fig 4 .

Table 4

\begin{tabular}{|l|c|}
\hline Settling Chamber Specifications & \\
\hline Length of section & $300 \mathrm{~mm}$ \\
\hline Entrance and exit area & $570 \times 570 \mathrm{~mm}^{2}$ \\
\hline
\end{tabular}

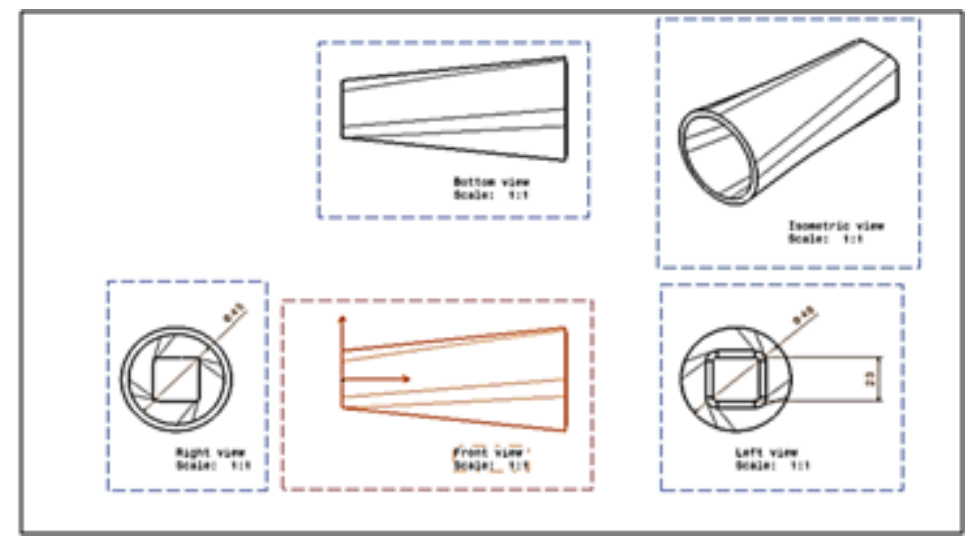

Figure 3: Diffuser Section Layout.

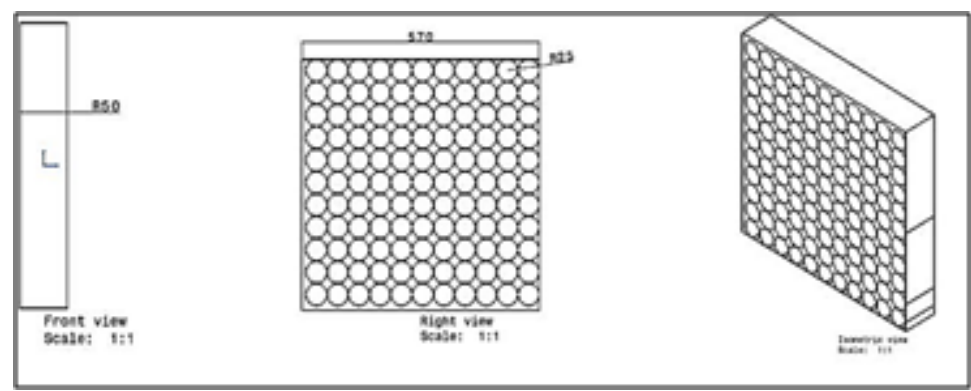

Figure 4: Honeycomb Structure.

\section{Fan and Fan Hub}

A major work in designing fan is that it must provide a required velocity at test Section $(70 \mathrm{~m} / \mathrm{s})$ and to resist the pressure drop along the Wind Tunnel. Usually a safety factor may be considered to be $25 \%$.The diffuser fan and hub are shown in fig. 5 and fig. 6. respectively.

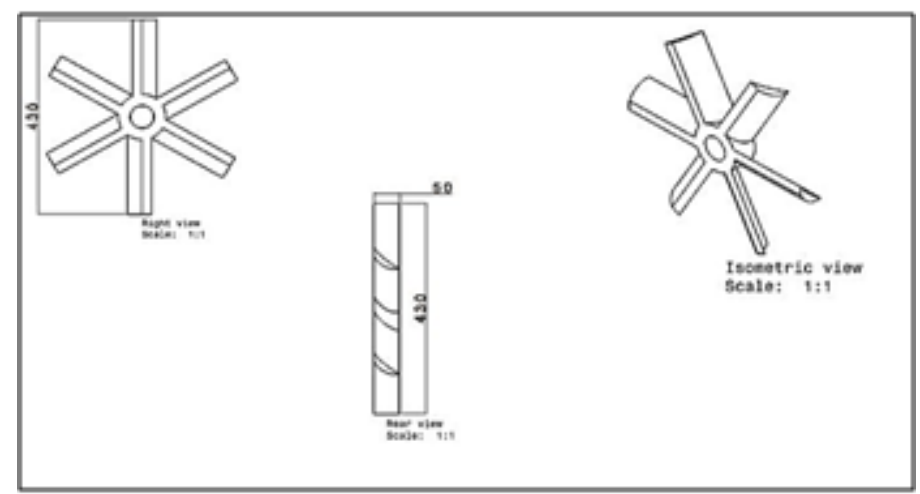

Figure 5: Diffuser Fan Specifications. 


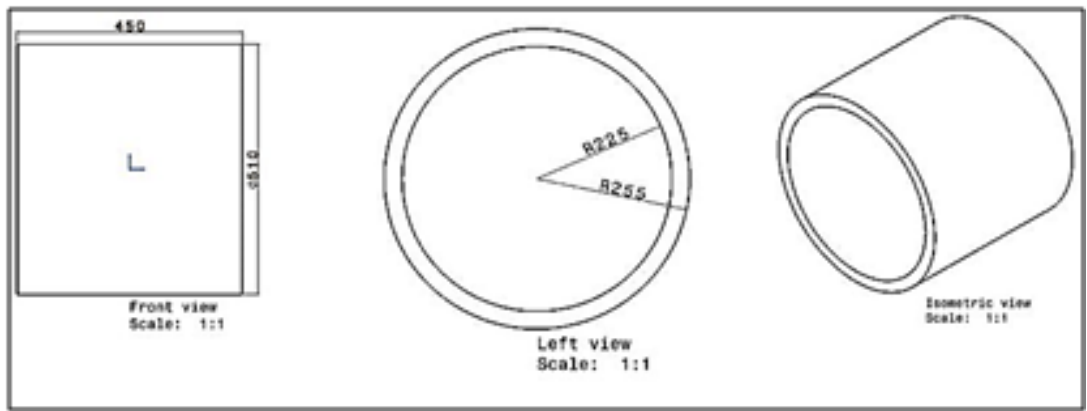

Figure 6: Diffuser Fan Hub.

Table 5

\begin{tabular}{|l|c|}
\hline \multicolumn{1}{|c|}{ Fan Specifications } & \\
\hline Type of fan & Axial simple fan \\
\hline Hub diameter & $570 \times 570 \mathrm{~mm}^{2}$ \\
\hline Blade length & $450 \mathrm{~mm}$ \\
\hline No. of blades & 6 \\
\hline Tilt angle of blades & $30^{0}$ \\
\hline Outer diameter of fan & $5100 \mathrm{rpm}$ \\
\hline Number of revolution per minute & $2380 \mathrm{rpm}$ \\
\hline Thickness of steel sheet used for blade manufacturing & $6 \mathrm{~mm}$ \\
\hline
\end{tabular}

\section{Airfoil}

An airfoil has to be chosen in order to test the working capabilities of the wind tunnel test rig. The chosen specifications for experimentation and analysis is given as stated below. The designed airfoil is shown in fig. 7 .

Table 6

\begin{tabular}{|l|c|}
\hline Airfoil Specifications & \\
\hline Aspect Ratio & $1.14: 1$ \\
\hline Chord length & $150 \mathrm{~mm}$ \\
\hline Span & $170 \mathrm{~mm}$ \\
\hline
\end{tabular}

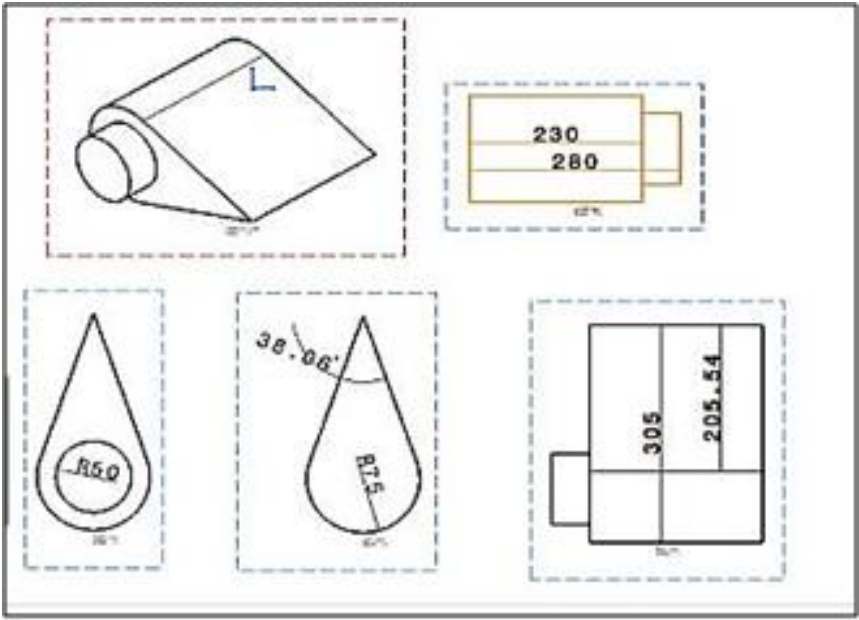

Figure 7: Airfoil Line Diagram. 


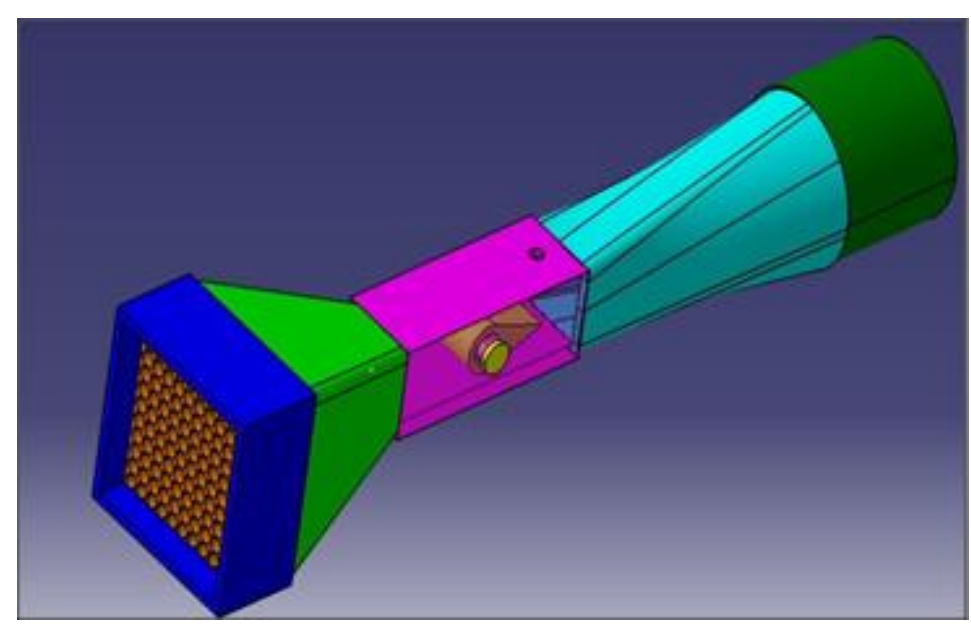

Figure 8: Wind Tunnel Design.

An overall test rig setup for analysis of aerodynamic bodies is finally designed as shown in fig. 8. It is then simulated in CFX tool.

\section{EXPERIMENTATION \& SIMULATION}

Test object is kept in the testing chamber, by fixing it on a support. This support is in turn connected to the force measuring sensor (Strain Gauge). Suction fan is switched on which makes the smoke to pass over the object. Honeycomb provided at the entrance makes the flow laminar. Next both inlet and exhaust fans are switched on and air is allowed to pass over the test aerodynamic body. The lift generated by the specimen is noted in the Strain Gauge. Next the lift generated is noted for various angles of attacks. Next the velocity of the air is varied using a fan speed regulator. The effect of velocity on aerofoil lift for different aerofoil models for various angles of attack is tabulated and then analysed with the help of results so obtained.

The airfoil chosen for experimentation and analysis is CLARK Y. The airfoil has a chord length of 150mm and span of $170 \mathrm{~mm}$, which is equal to the width of the test section. In order to measure the pressure distribution on the airfoil surface, pressure taps were provided on each and every hole provided on airfoil section, as shown in Fig. 13. The airfoil was mounted with the help of a frame inside the Test Section. With the help of a round protractor, the desired angle of attack for the airfoil was set. The airfoil was held at this angle using a screw mechanism. Measurements of surface pressure distribution were carried out with the help of water tube manometers to which all the pressure taps were connected. A slot was provided over the top wall of the test section for traversing the pitot tube to measure the velocity, at the desired location. The Test Section blockage was checked at the maximum angle of attack of $15^{\circ}$. As the aircraft fly at low angles of attack, most of the measurements such as those of lift and drag forces and velocity survey over the airfoil were limited to this angle of attack. A maximum blockage ratio of about $6 \%$ was found.

Simulation was carried out and the test section is found to obtain approximately a constant velocity (nearly 70 $\mathrm{m} / \mathrm{s}$ ) which indicates that the design is fair enough since there is no flow separation at test section neither at least no thickening of boundary layer at this region which may lead to measurement errors. 


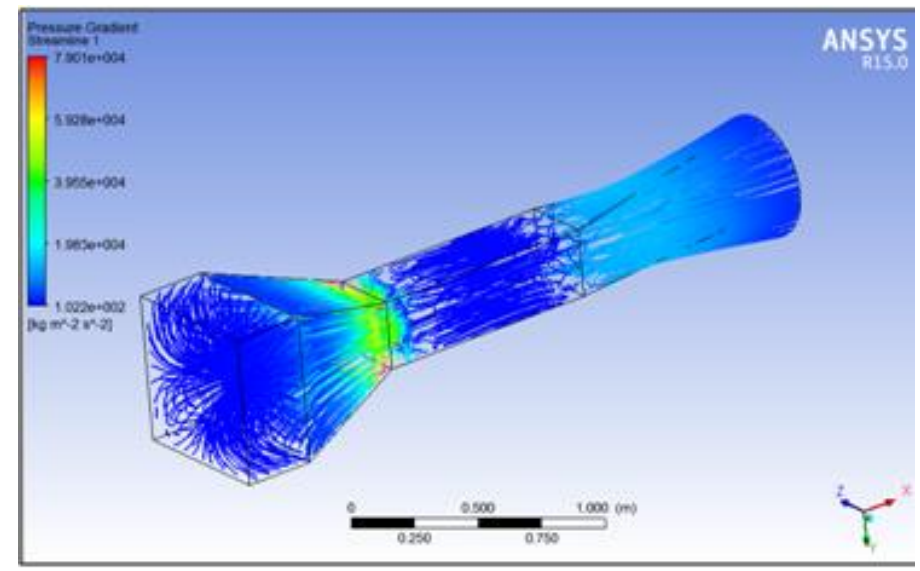

Figure 9: Pressure Contour.

\section{: centedine}

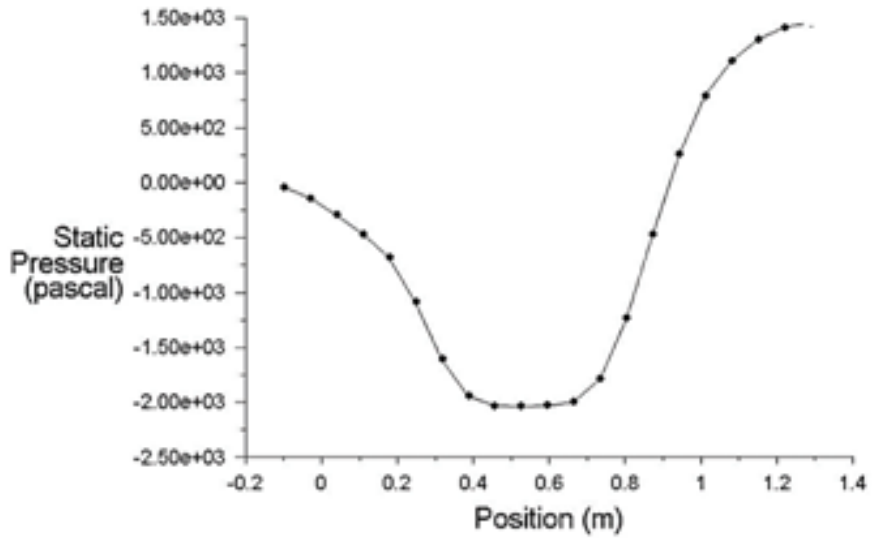

Figure 10: Static Pressures at Different Locations.

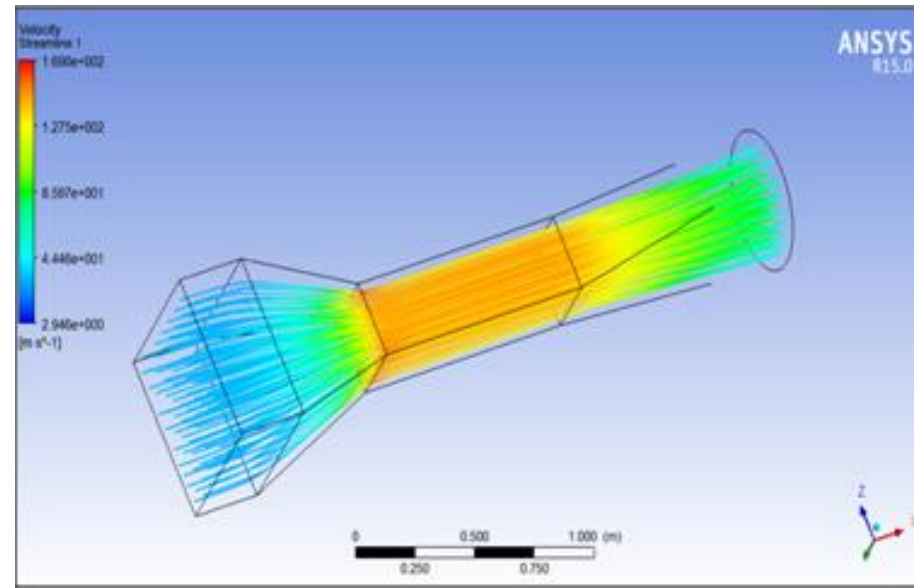

Figure 11: Velocity Contour. 


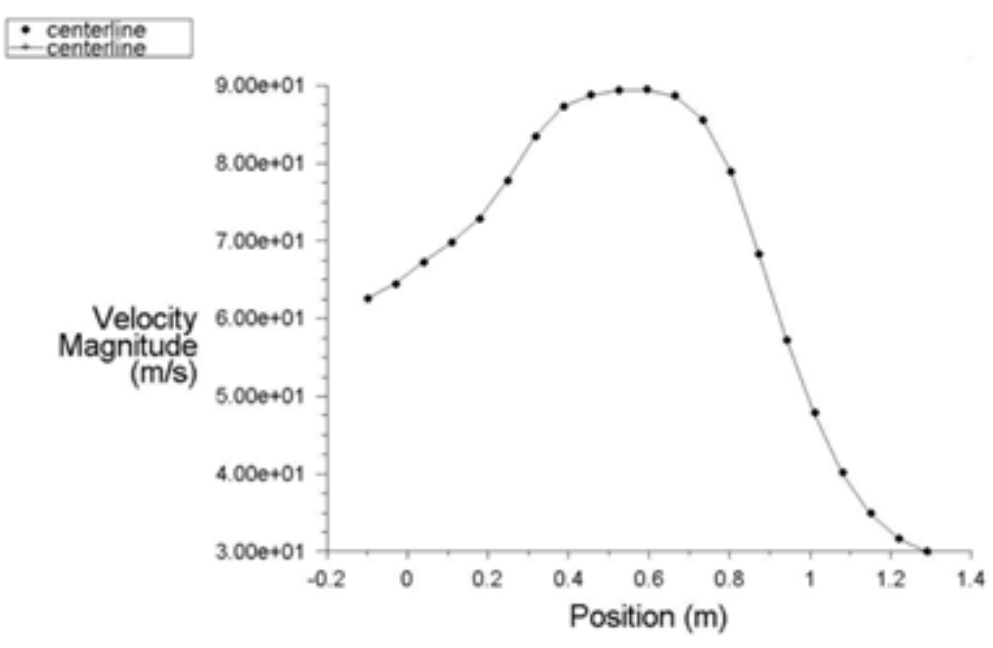

Figure 12: Velocity Magnitude at Different Positions.

Figs $9 \& 11$ represent the pressure gradient and velocity streamlines for flow through a simulated wind tunnel test rig whereas figs $10 \& 12$ represent the variation of static pressure and velocity magnitude at varying locations of pressure taps as shown in fig 13.

\section{RESULTS \& DISCUSSIONS}

CFD simulation on Clark Y Airfoil on Low Speed Open Type Wind Tunnel at constant velocity is analyzed using CFX. The data is shown as mentioned here.

Free Stream Flow Velocity $(\mathrm{V})=20 \mathrm{~m} / \mathrm{s}$

Free Stream Dynamic Pressure $\left(\mathrm{Q}_{\infty}\right)=0.5$ x Density x V $\mathrm{V}^{2}=245 \mathrm{~N} / \mathrm{m}^{2}$

Chord Length $(\mathrm{c})=15 \mathrm{~cm}$, Span Length $(\mathrm{s})=17 \mathrm{~cm}$

Area of Airfoil $(\mathrm{A})=0.15 \mathrm{~m} \times 0.17 \mathrm{~m}=0.0255 \mathrm{~m}^{2}$

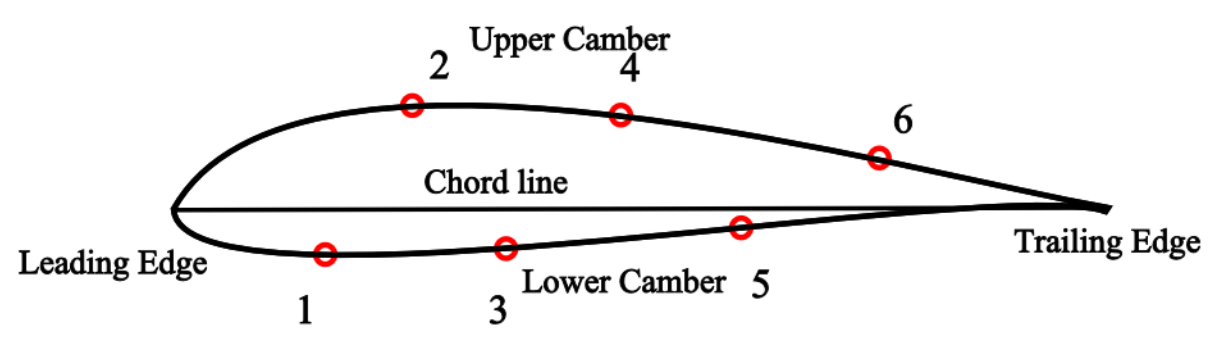

Figure 13: CLARK Y Airfoil with Pressure Taps (1-6).

The flow characteristics over airfoil are studied by carrying out CFD simulation in a low speed designed wind tunnel. The change in pressure distribution over the surface of the CLARK Y airfoil was obtained, along with which the lift and drag forces were calculated and mean velocity profiles were also estimated over the surface. Simulations are repeated out by varying the angle of attack, from $-15^{\circ}$ to $15^{\circ}$. 


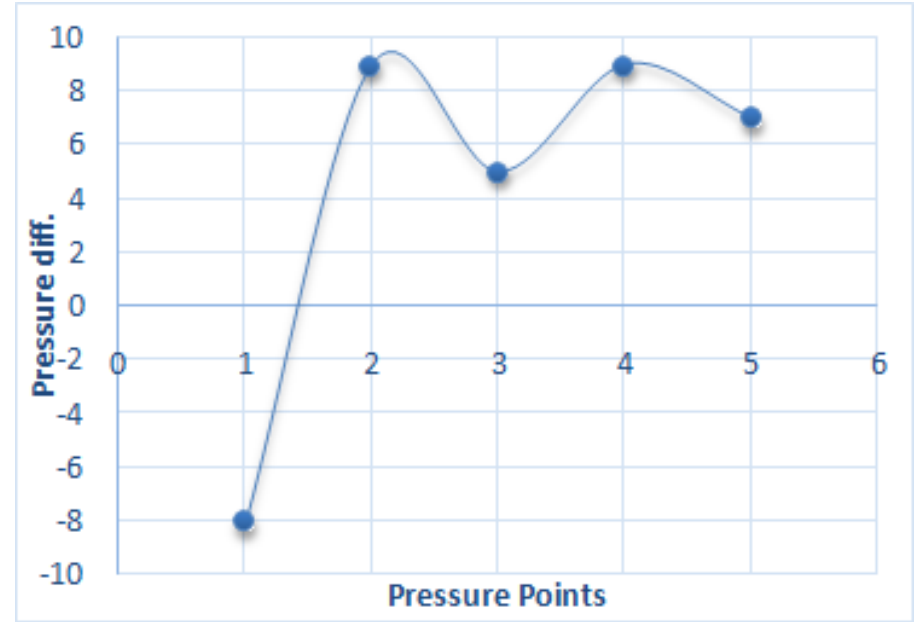

Figure 14: Pressure Points Vs Pressure Diff.

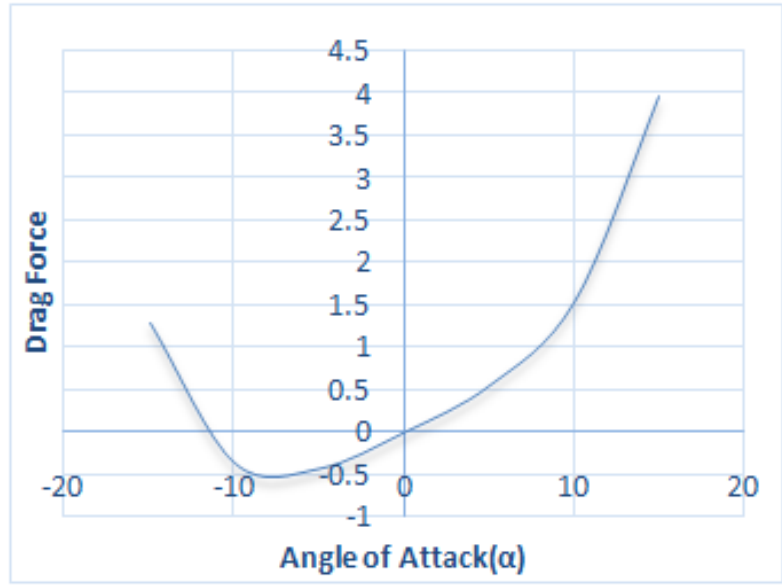

Figure 15: Angle of Attack ( $\alpha$ ) vs Drag Force.

From the Fig. 14, the variation of pressure at different pressure points from 1 to 6 is shown at a constant ground clearance with different angles of attack. From the first line i.e. series1 it is clearly shown that when the angle of attack is zero the pressure at points $1,3,5$ are declining. This is because the pressure distribution on the top surface of the airfoil is a streamlined flow and from just above the leading edge the velocity is increasing. We know from the Bernoulli's equation when velocity increases pressure decreases causing energy balance. The same phenomenon is proved.

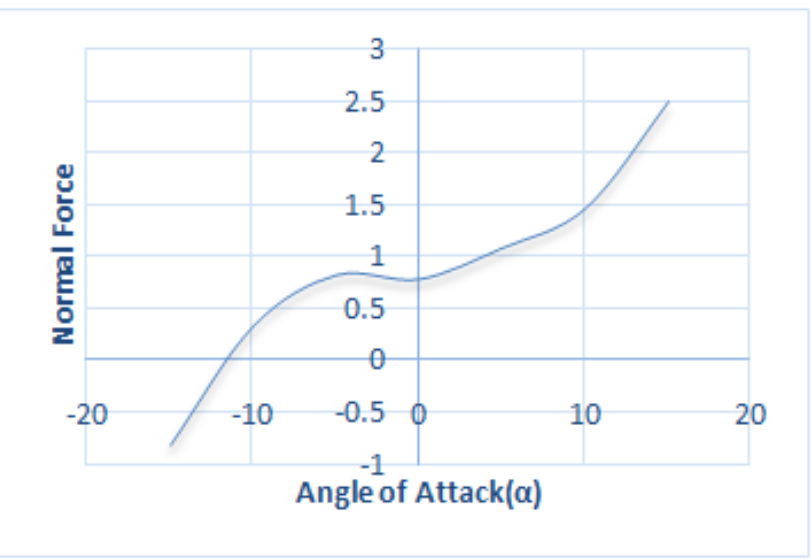

Figure 16: Angle of Attack ( $\alpha$ ) vs Normal Force. 


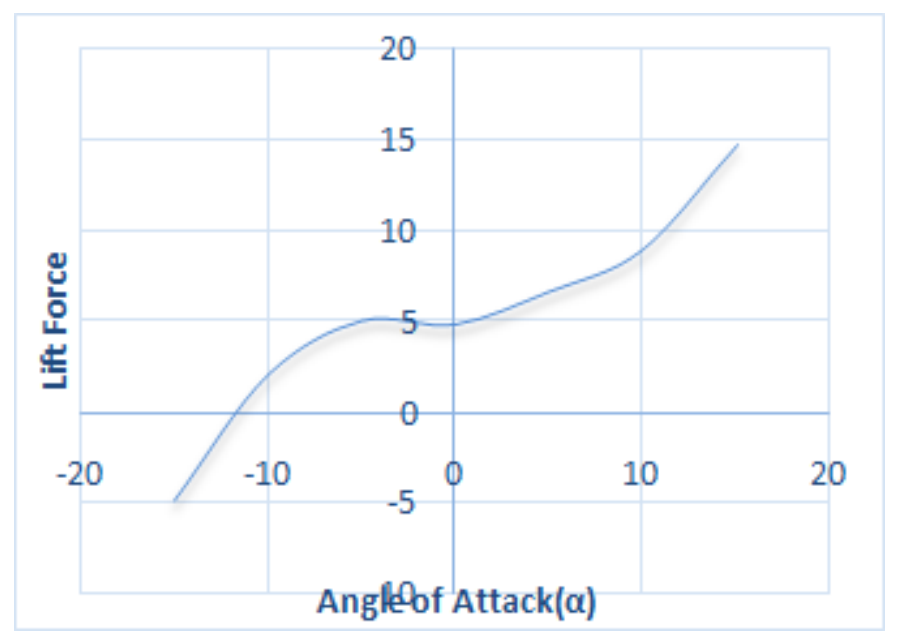

Figure 17: Angle of Attack ( $\alpha$ ) vs Lift Force.

The nature of the pressure distribution curve and the normal force distribution curve is similar. The normal distribution curve (fig. 15) is nothing but the lift force at each strip. It is the cosine component of the pressure force at each strip of the air foil. Angle of each pressure force to the vertical at each angle of attack is given in the table. From the first line i.e. series 1 it is clearly shown that when the angle of attack is zero the normal force from point1,3,5 gradually decreasing to zero. This is because the pressure distribution on the top surface of the air foil is gradually decreasing.

The lift force vs the angle of attack plot (fig. 16) shows the effect of lift force with increasing of angle of attack. Each line shows the variation of lift force with angle of attack at different ground clearance. When angle of attack is zero, the lift force is also zero for different ground clearance. The pressure force both the sides of the air foil are same. When we increase the angle of attack to 5 degree the lift force increases. But, further increasing of angle of attack, the lift force decreases. This point is called as stall point. Stalling angle we have found is around 15 degrees.

\section{CONCLUSIONS}

A well-designed wind tunnel test rig is developed to carryout experimentation where the aerodynamic analysis of CLARK $\mathrm{Y}$ airfoil is carried out. The results so obtained are in good agreement with theoretically obtained data as well as simulation output which is done using CFX tool. CLARK Y airfoil is found to exhibit better stability characteristics before reaching stall condition and is also found to gain higher lift characteristics as the airfoil accelerates rapidly as lower altitudes with minimum ground clearance. No major significant pressure variations are observed above the airfoil and is found to perform well at all angles of attack.

\section{REFERENCES}

1. Robert Placek "The flow separation development analysis in subsonic and transonic flow regime of the laminar airfoil." A report on Transportation Research Procedia, Vol. 29, pp 323-329, 2018

2. Bruno Chanetz “A century of wind tunnels since Eiffel” Volume 345, Issue 8, pp 581-594, 2017

3. Calautit, J. K., Chaudhry, H. N., Hughes, B. R., \& Sim, L. F. (2014). A validated design methodology for a closed loop subsonic wind tunnel. Journal of Wind Engineering and Industrial Aerodynamics, 125, 180-194. https://doi.org/10.1016/j.jweia.2013.12.010 
4. Jafari, A., Ghanadi, F., Emes, M. J., Arjomandi, M., \& Cazzolato, B. S. (2019). Measurement of unsteady wind loads in a wind tunnel: Scaling of turbulence spectra. Journal of Wind Engineering and Industrial Aerodynamics, 193(July), 103955. https://doi.org/10.1016/j.jweia.2019.103955

5. Kaveh Ghorbanian, Mohammad Reza Soltani "Experimental investigation on turbulence intensity reduction in subsonic wind tunnels. " An Article on Aerospace Science and Technology, Vol 15, issue 2, pp 79-154, 2011

6. Ismail, John, J., Pane, E. A., Suyitno, B. M., Rahayu, G. H. N. N., Rhakasywi, D., \& Suwandi, A. (2020). Computational fluid dynamics simulation of the turbulence models in the tested section on wind tunnel. Ain Shams Engineering Journal, xxxx. https://doi.org/10.1016/j.asej.2020.02.012

7. Nguyen, Q. Y. (2014). Designing, Constructing, And Testing A Low-Speed Open-Jet Wind Tunnel. Journal of Engineering Research and Applications Www.Ijera.Com, 4(1), 243-246.

8. Carbó Molina, A., De Troyer, T., Massai, T., Vergaerde, A., Runacres, M. C., \& Bartoli, G. (2019). Effect of turbulence on the performance of VAWTs: An experimental study in two different wind tunnels. Journal of Wind Engineering and Industrial Aerodynamics, 193(July).

9. Guo, F., Ding, L., Gao, Z., Yu, L., \& Ji, J. (2020). Effects of wind flow and sidewall restriction on the geometric characteristics of propane diffusion flames in tunnels. Energy, 198, 117332.

10. Vergaerde, A., De Troyer, T., Carbó Molina, A., Standaert, L., \& Runacres, M. C. (2019). Design, manufacturing and validation of a vertical-axis wind turbine setup for wind tunnel tests. Journal of Wind Engineering and Industrial Aerodynamics, 193(May).

11. Arvindkumar Drave \& K. P. Mishra, "Development of Energy Efficient Cooking Systems for Rural Masses “, BEST: International Journal of Management, Information Technology and Engineering (BEST: IJMITE), Vol. 4, Issue 2, pp. 37-48

12. Samanwita Roy, "Comparative Flow Analysis of NACA S6061 and NACA 4415 Aerofoil by Computational Fluid Dynamics ", International Journal of MechanicalEngineering (IJME), Vol. 7, Issue 2,pp.9-18

13. Mustafa M. A. Hussein, Manal M. Abdullah, Ghuson H. Mohammed \& Kadhim A Aadem "I-V Characteristics of CdTe/PtNPs/AL2O3/PtNPs/Si Thin Film Solar Cell”, BEST: International Journal of Humanities, Arts, Medicine and Sciences (BEST: IJHAMS), Vol. 2, Issue 7, pp. 21-26

14. Suresh Pittala \& Awash Tekle Tafere, "CFD Analysis for Linear Blade Cascade of a Turbine ", International Journal of Mechanical Engineering (IJME), Vol. 3, Issue 3, pp. 37-46 

